\title{
A single nucleotide polymorphism of AIRE gene located in the $21 q 22.3$ increases the risk of rheumatoid arthritis
}

\author{
Yuan-Sheng $\mathbf{X u}^{1}, \mathbf{X i}^{\mathrm{i}} \mathrm{Jia}^{\mathrm{J}} \mathrm{Jiang}^{2}$ and Jian-Min Chen ${ }^{1}$ \\ ${ }^{1}$ Department of Orthopaedics, Bayi Hospital Affiliated to Nanjing University of Chinese Medicine, Nanjing 210002, China \\ ${ }^{2}$ Department of Orthopaedics, Changzhou No.2 People's Hospital, Changzhou 213003, China \\ Correspondence to: Xi-Jia Jiang, email: xijiajiangnb@126.com \\ Jian-Min Chen, email: yingyuomed@sina.com
}

Keywords: AIRE, single nucleotide polymorphism, rheumatoid arthritis

Received: March 09, 2017 Accepted: April 15, $2017 \quad$ Published: May 10, 2017

Copyright: Xu et al. This is an open-access article distributed under the terms of the Creative Commons Attribution License 3.0 (CC BY 3.0), which permits unrestricted use, distribution, and reproduction in any medium, provided the original author and source are credited.

\section{ABSTRACT}

Several studies addressed the association of autoimmune regulator (AIRE) gene polymorphism with the risk of rheumatoid arthritis (RA); however, their conclusions were inconsistent. For better investigating the effects of this polymorphism on the risk of RA, we conducted this study to evaluate the role of AIRE rs2075786 polymorphism in the risk of RA. Four eligible studies involving 6,755 cases and 7,970 controls were identified by searching the databases of PubMed, CNKI and EMBASE up to February 2017. Our study revealed that AIRE rs2075786 polymorphism was associated with an increased risk of RA under all genetic models. In the subgroup analysis, AIRE rs2075786 polymorphism contributed to RA susceptibility among Asians, but not among Caucasians. To summarize, this meta-analysis confirms that AIRE rs2075786 polymorphism may play a significant role in increasing the risk of RA. Stratification analysis by ethnicity reveals that AIRE rs2075786 polymorphism is associated with an increased risk of RA among Asians, but not among Caucasians. These findings need further validation in the large multicenter case-control studies.

\section{INTRODUCTION}

Rheumatoid arthritis (RA), is a chronic inflammatory autoimmune disease in which hyperplasia, hypertrophy and angiogenesis of synovial tissue contribute to inflammatory joint destruction [1]. In industrialised countries, RA affects $0.5-1.0 \%$ of adults, with $5-50$ per 100000 new cases annually $[2,3] .50 \%$ of the risk for development of RA is attributable to genetic factors [4]. Moreover, the role of common genetic variation in determining the range of individual susceptibility within the population is increasingly recognized [5].

The autoimmune regulator (AIRE) gene is located in the $21 \mathrm{q} 22.3$ region, and is $12.5 \mathrm{~kb}$ in length, and contains 14 exons that encode a 545 amino acid protein of $58 \mathrm{kD}[6$, 7]. AIRE plays a key role in shaping central immunological tolerance by facilitating negative selection of $\mathrm{T}$ cells in the thymus, building the thymic microarchitecture, and inducing a specific subset of regulatory T cells [8]. Moreover, many studies demonstrated that thymus of AIRE knockout mice appears normal in terms of thymocytes number, but AIRE knockout mice and autoimmune polyendocrinopaythy-candidiasis-ectodermal dystrophy (APECED) patients, both exhibits autoimmune disease [9-11]. Liu et al. found significantly lower levels of AIRE expression were associated with the development of thymoma-related autoimmune diseases [12]. Furthermore, Terao et al. found that downregulation of AIRE by genetic polymorphisms may trigger auto-inflammation in RA [13].

Over 100 mutations in the AIRE gene have been reported in the Human Gene Mutation Database, varying from single nucleotide substitutions to large deletions spread out across the coding sequence. AIRE gene polymorphism has been studied in various autoimmune disease, such as Graves' disease [14], type 1 diabetic [15] and alopecia areata [16]. A GWAS study identified the strong association between rs2075786 polymorphism and RA risk. However, the association between AIRE rs2075786 polymorphism and RA risk remains obscure because of contradictory and inconclusive findings of other published studies. Thus, we undertook this meta-analysis to evaluate whether AIRE rs2075786 polymorphism was associated with RA risk. 


\section{RESULTS}

\section{Study characteristics}

70 articles were retrieved after initial search. The selection process of eligible articles is shown in Figure 1. 44 articles were excluded; of which 15 were duplicates and 29 were unrelated to the topic. Among of the remaining 26 articles, 14 articles did not investigate the association between AIRE rs2075786 polymorphism and RA risk; one article was not a case-control study; 4 articles did not have sufficient genotype frequencies; 3 articles were reviews. Finally, 4 studies were available for our topic in this metaanalysis, consisting of 6,755 cases and 7,970 controls. The detailed characteristics of the included studies are listed in Table 1.

\section{Quantitative synthesis of data}

In the overall analysis, AIRE rs2075786 polymorphism showed positive correlation with RA risk and could be viewed as a risk factor of RA under five models (Table 2). In the allele model, individuals carrying the AA genotype had a $19 \%$ higher risk of RA compared to GG genotype carriers (A vs. G: OR, 1.19; 95\% CI, $1.14-1.25, P<0.001$, Figure 2). Subgroup analysis by ethnicity revealed that AIRE rs2075786 polymorphism could contribute to the risk of RA among Asians (Table 3), but not among Caucasians (AA+GA vs. GG: OR, 1.42; $95 \%$ CI, 1.13-1.78, $P=0.002$, Figure 3). When stratified by Hardy-Weinberg equilibrium (HWE) status, significant associations were also observed between AIRE rs2075786 polymorphism and RA risk (Table 3 ).

Sensitivity analysis using the leave-one-out crossvalidation method was conducted to assess the impact of each single study on the overall risk estimates. The omission of each individual study did not have substantial influence on the risk estimates, supporting the credibility and reliability of this meta-analysis. Publication bias was assessed by Begg's funnel plot and quantitative Egger's test (Table 2). We did not find any obvious publication bias for the association between AIRE rs2075786 polymorphism and RA risk (AA vs. GG, Figure 4)

\section{DISCUSSION}

AIRE is a transcriptional regulator primarily expressed in medullary thymic epithelial cells, and plays

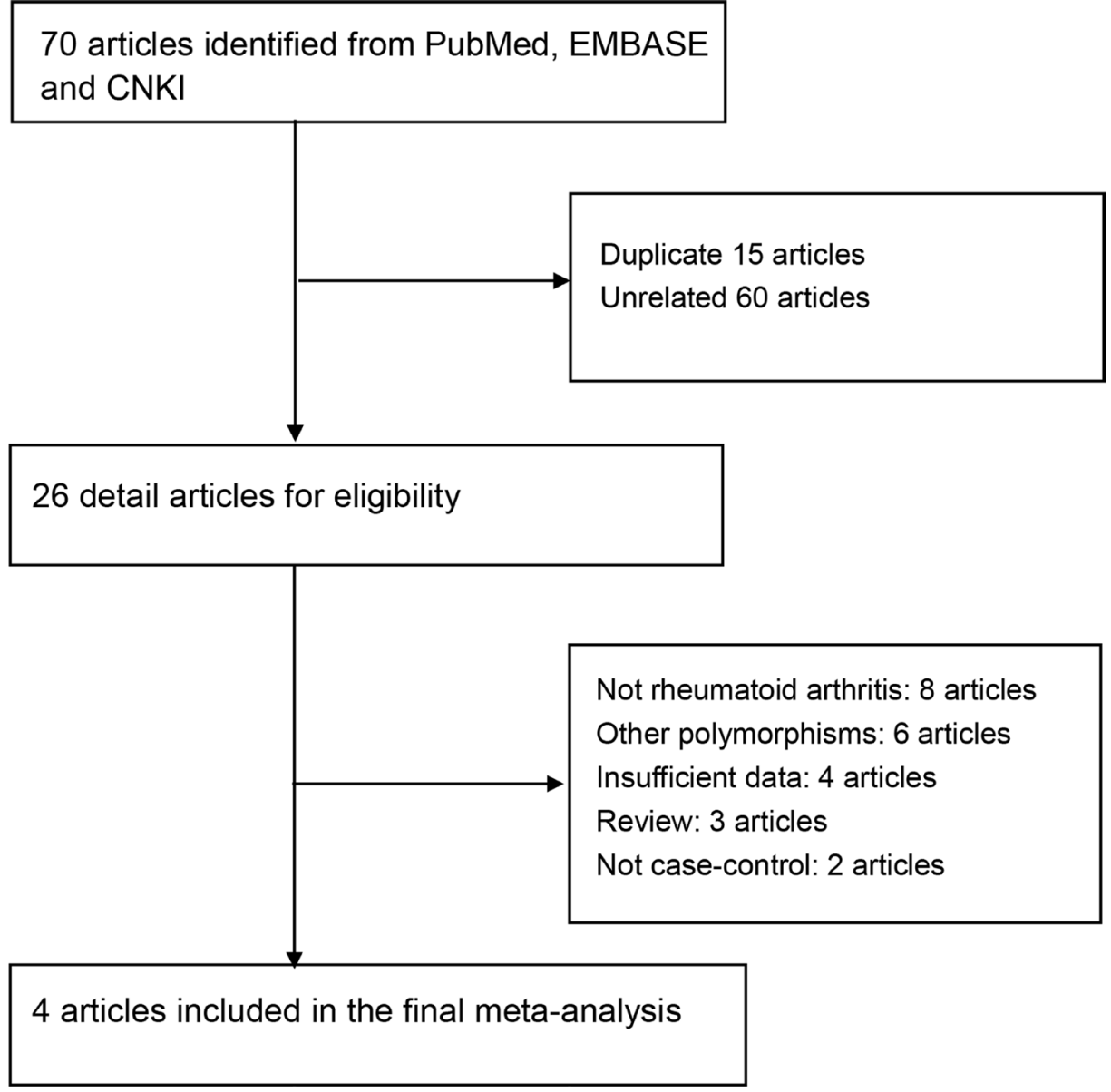

Figure 1: Selection for eligible citations included in this meta-analysis. 
Table 1: Characteristics of included studies for the association between rs751402 and rheumatoid arthritis risk

\begin{tabular}{lcccccccccccccc}
\hline \multicolumn{1}{c}{ Author } & year & Country & Ethnicity & SOC & $\begin{array}{c}\text { Genotype } \\
\text { method }\end{array}$ & & Case & & Control & HWE & NOS \\
& & & & & & CC & CT & TT & CC & CT & TT & \\
\hline Feng & 2015 & China & Asian & HB & TaqMan & 173 & 350 & 168 & 273 & 364 & 163 & 0.013 & 6 \\
Garcia-Lozano & 2013 & Spain & Caucasian & HB & TaqMan & 364 & 95 & 6 & 371 & 95 & 6 & 0.977 & 6 \\
Shao & 2013 & China & Asian & HB & SNaPshot assay & 61 & 116 & 55 & 105 & 115 & 53 & 0.038 & 7 \\
Terao & 2011 & Japan & Asian & HB & TaqMan & 2091 & 2502 & 774 & 2811 & 2857 & 757 & 0.450 & 8 \\
\hline
\end{tabular}

SOC, source of controls; PB, population-based controls; HB, hospital-based controls; HWE, Hardy-Weinberg Equilibrium; NOS, Newcastle-Ottawa Scale.

Table 2: Analysis for the effect of rs2075786 on the risk of rheumatoid arthritis

\begin{tabular}{lcccccc}
\hline \multicolumn{1}{c}{ Genetic model } & \multicolumn{2}{c}{ Statistics } & \multicolumn{2}{c}{ Heterogeneity } & \multicolumn{2}{c}{ Publication bias } \\
& OR(95\%CI) & $\boldsymbol{P}$ & $\boldsymbol{P}_{\text {heterogeneity }}$ & $\mathbf{I}^{\mathbf{2}} \mathbf{( \% )}$ & $\boldsymbol{P b e g g}$ & $\boldsymbol{P E g g e r}$ \\
\hline Allele (A vs. G) & $\mathbf{1 . 1 9}(\mathbf{1 . 1 4 , 1 . 2 5})$ & $<0.001$ & 0.223 & 31.5 & 0.497 & 0.664 \\
Dominant (AA+GA vs. GG) & $\mathbf{1 . 3 3}(\mathbf{1 . 1 0 , 1 . 6 0 )}$ & 0.004 & 0.035 & 65.3 & 0.497 & 0.517 \\
Recessive (AA vs. GA+GG) & $\mathbf{1 . 2 6}(\mathbf{1 . 1 5 , 1 . 3 9 )}$ & $<0.001$ & 0.985 & 0.0 & 0.497 & 0.419 \\
Homozygous (AA vs. GG) & $\mathbf{1 . 4 2}(\mathbf{1 . 2 8 , 1 . 5 7 )}$ & $<0.001$ & 0.508 & 0.0 & 1.000 & 0.601 \\
Heterozygous (GA vs. GG) & $\mathbf{1 . 2 9}(\mathbf{1 . 0 7 , 1 . 5 7 )}$ & 0.009 & 0.046 & 62.5 & 0.497 & 0.448 \\
\hline
\end{tabular}

*Bold values are statistically significant $(P<0.05)$.

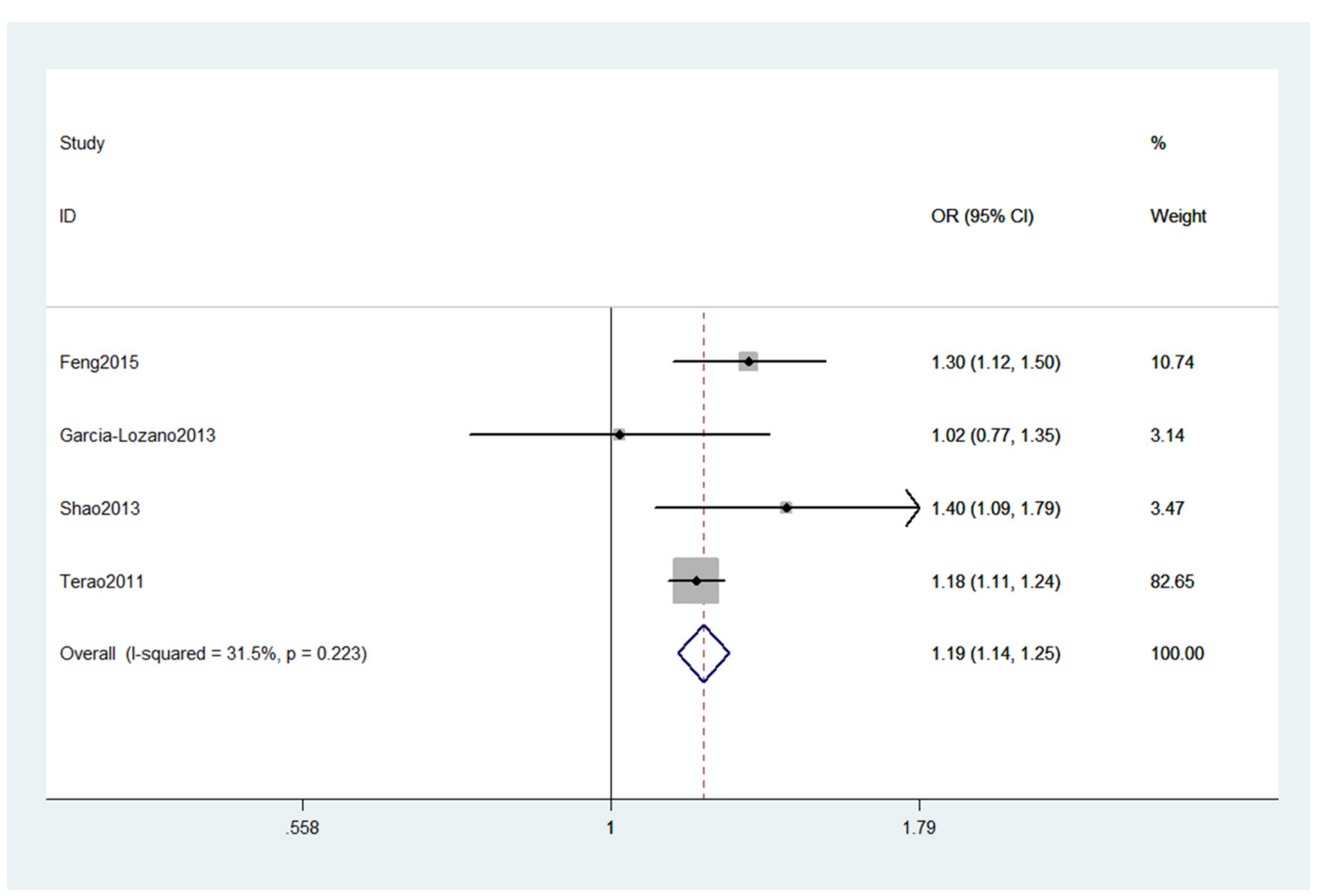

Figure 2: Forest plot shows odds ratio for the association between AIRE gene rs2075786 polymorphism and RA risk (A vs. G). 
Table 3: Summary of the subgroup analyses in this meta-analysis

\begin{tabular}{|c|c|c|c|c|c|c|}
\hline Comparison & Category & Category & Studies & OR $(95 \%$ CI) & $P$-value & $\begin{array}{c}P \text { for } \\
\text { heterogeneity }\end{array}$ \\
\hline \multirow[t]{2}{*}{ A vs. $G$} & Ethnicity & $\begin{array}{c}\text { Asian } \\
\text { Caucasian }\end{array}$ & $\begin{array}{l}3 \\
1\end{array}$ & $\begin{array}{l}1.20(\mathbf{1 . 1 4}, \mathbf{1 . 2 6}) \\
1.02(0.77,1.35)\end{array}$ & $\begin{array}{c}<0.001 \\
0.908\end{array}$ & $\begin{array}{l}0.206 \\
\mathrm{~N} / \mathrm{A}\end{array}$ \\
\hline & HWE & $\begin{array}{l}\text { No } \\
\text { Yes }\end{array}$ & $\begin{array}{l}2 \\
2\end{array}$ & $\begin{array}{l}1.32(1.17,1.50) \\
1.17(1.11,1.23)\end{array}$ & $\begin{array}{l}<0.001 \\
<0.001\end{array}$ & $\begin{array}{l}0.626 \\
0.327\end{array}$ \\
\hline \multirow[t]{2}{*}{$\mathrm{AA}+\mathrm{GA}$ vs. GG } & Ethnicity & $\begin{array}{c}\text { Asian } \\
\text { Caucasian }\end{array}$ & $\begin{array}{l}3 \\
1\end{array}$ & $\begin{array}{l}\mathbf{1 . 4 2}(\mathbf{1 . 1 3}, \mathbf{1 . 7 8}) \\
1.02(0.75,1.39)\end{array}$ & $\begin{array}{l}0.002 \\
0.905\end{array}$ & $\begin{array}{l}0.031 \\
\mathrm{~N} / \mathrm{A}\end{array}$ \\
\hline & HWE & $\begin{array}{l}\text { No } \\
\text { Yes }\end{array}$ & $\begin{array}{l}2 \\
2\end{array}$ & $\begin{array}{l}1.60(1.32,1.94) \\
1.19(1.06,1.34)\end{array}$ & $\begin{array}{c}<0.001 \\
0.003\end{array}$ & $\begin{array}{l}0.590 \\
0.274\end{array}$ \\
\hline \multirow[t]{2}{*}{ AA vs.GA+GG } & Ethnicity & $\begin{array}{c}\text { Asian } \\
\text { Caucasian }\end{array}$ & $\begin{array}{l}3 \\
1\end{array}$ & $\begin{array}{l}\mathbf{1 . 2 6}(\mathbf{1 . 1 5}, \mathbf{1 . 3 9}) \\
1.02(0.33,3.17)\end{array}$ & $\begin{array}{c}<0.001 \\
0.979\end{array}$ & $\begin{array}{c}0.994 \\
\text { N/A }\end{array}$ \\
\hline & HWE & $\begin{array}{l}\text { No } \\
\text { Yes }\end{array}$ & $\begin{array}{l}2 \\
2\end{array}$ & $\begin{array}{l}1.26(1.02,1.56) \\
1.26(1.13,1.40)\end{array}$ & $\begin{array}{c}0.031 \\
<0.001\end{array}$ & $\begin{array}{l}0.914 \\
0.710\end{array}$ \\
\hline \multirow[t]{2}{*}{ AA vs. GG } & Ethnicity & $\begin{array}{c}\text { Asian } \\
\text { Caucasian }\end{array}$ & $\begin{array}{l}3 \\
1\end{array}$ & $\begin{array}{l}\mathbf{1 . 4 2}(\mathbf{1 . 2 8 , 1 . 5 8 )} \\
1.02(0.33,3.19)\end{array}$ & $\begin{array}{c}<0.001 \\
0.974\end{array}$ & $\begin{array}{l}0.368 \\
\mathrm{~N} / \mathrm{A}\end{array}$ \\
\hline & HWE & $\begin{array}{l}\text { No } \\
\text { Yes }\end{array}$ & $\begin{array}{l}2 \\
2\end{array}$ & $\begin{array}{l}1.67(1.30,2.13) \\
1.37(1.22,1.54)\end{array}$ & $\begin{array}{l}<0.001 \\
<0.001\end{array}$ & $\begin{array}{l}0.747 \\
0.609\end{array}$ \\
\hline \multirow[t]{2}{*}{ GA vs. GG } & Ethnicity & $\begin{array}{c}\text { Asian } \\
\text { Caucasian }\end{array}$ & $\begin{array}{l}3 \\
1\end{array}$ & $\begin{array}{l}1.38(\mathbf{1 . 0 9}, \mathbf{1 . 7 6}) \\
1.02(0.74,1.40)\end{array}$ & $\begin{array}{l}0.008 \\
0.907\end{array}$ & $\begin{array}{l}0.033 \\
\mathrm{~N} / \mathrm{A}\end{array}$ \\
\hline & HWE & $\begin{array}{l}\text { No } \\
\text { Yes }\end{array}$ & $\begin{array}{l}2 \\
2\end{array}$ & $\begin{array}{l}1.57(1.28,1.93) \\
1.17(1.08,1.26)\end{array}$ & $\begin{array}{l}<0.001 \\
<0.001\end{array}$ & $\begin{array}{l}0.577 \\
0.390\end{array}$ \\
\hline
\end{tabular}

SOC, source of controls; PB, population-based controls; HB, hospital-based controls; HWE: Hardy-Weinberg equilibrium.

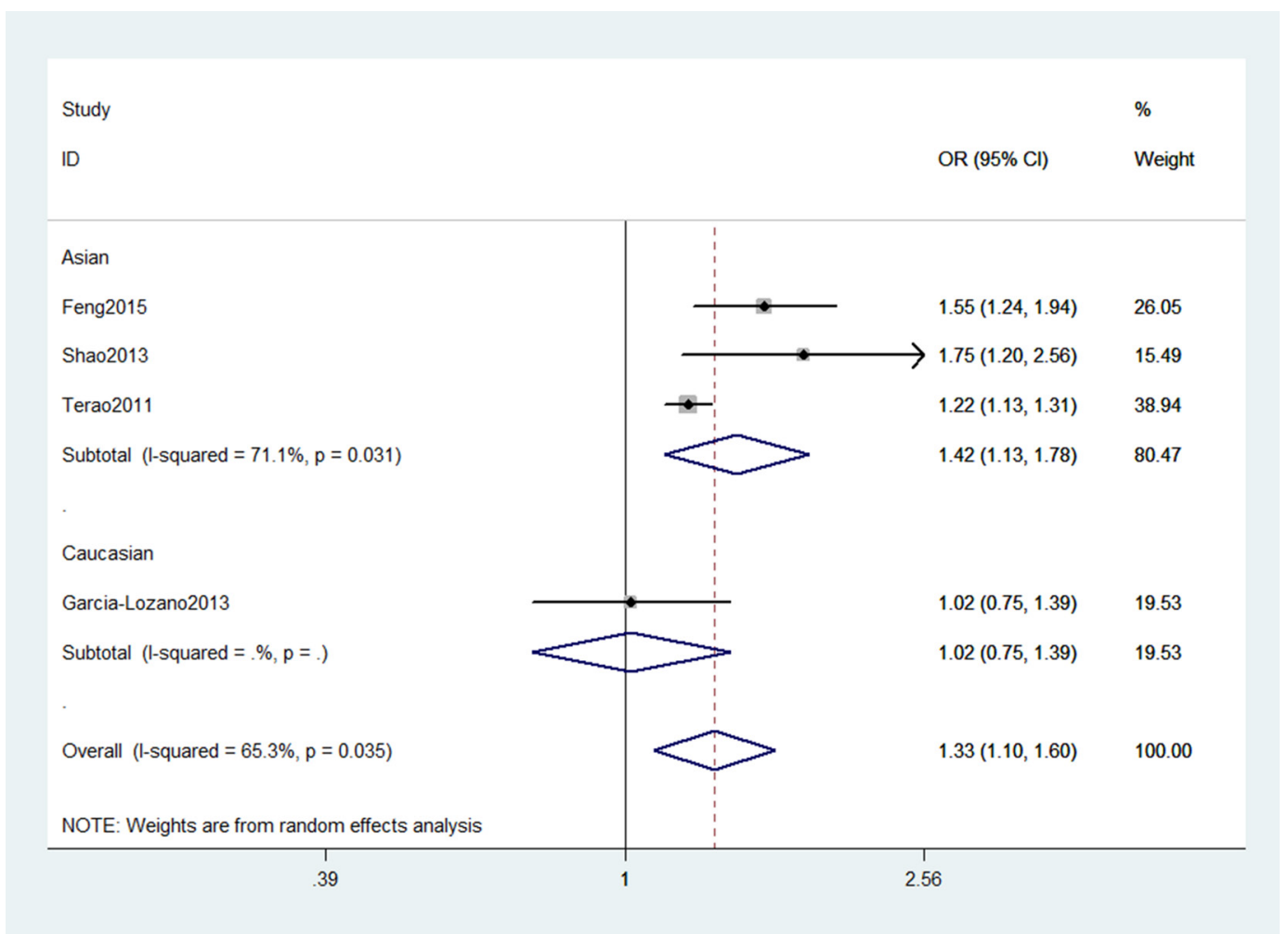

Figure 3: Stratification analyses of ethnicity shows odds ratio for the association between AIRE gene rs2075786 polymorphism and $\mathrm{RA}$ risk (AA+GA vs. GG). 
a functional role in thymocyte education and negative selection by controlling the expression of peripheral antigens in thymus [17]. AIRE in peripheral organs may provide hints to the involvement of AIRE in the predisposition or progression in RA [13]. According to the GEO database, the risk allele of rs2075876 polymorphism decreased the transcription level of AIRE. A series of studies started to investigate the role of AIRE rs2075786 polymorphism in the risk of RA, but with inconsistent results.

A GWAS study conducted by Terao et al. found that AIRE gene rs2075786 polymorphism increased the risk of RA among the Japanese population [13]. The significant association was also observed in the subsequent studies among Chinese Han populations [18, 19]. However, Garcia-Lozano et al. failed to replicate this association in a Caucasian population [20]. Our meta-analysis suggested that AIRE rs2075786 polymorphism could contribute to the risk of RA, especially among Asians. The results were consistent with the included studies from Asia. A possible explanation for the difference between Asians and Caucasians is that AIRE rs2075786 polymorphism may have an ethnicity-specific effect. According to 1000 Genomes Browser, A allele frequency in China's Beijing population is 0.8155 , while in the Spanish population of 0.2710 . Our results found that the A allele frequency was 0.3715 in Asians, which was higher than that of Caucasians (0.1142). Except for different distribution of gene functional polymorphisms among different races, we thought the following reasons including small sample size of single study, clinical heterogeneity, different environments, or uncorrected multiple hypothesis testing may explain the inconsistent findings between Caucasian populations and Asian populations. It is noteworthy that the sample sizes of Caucasians and Asians were limited in this meta-analysis. Therefore, we should interpret the data with caution.

High heterogeneities were observed in the dominant $\left(P_{\text {heterogeneity }}=0.035, \mathrm{I}^{2}=65.3\right)$ and heterozygous models $\left(P_{\text {heterogeneity }}=0.046, \mathrm{I}^{2}=62.5\right)$, which may have effects on our results. Subgroup analyses and sensitivity analysis were conducted to uncover the source of heterogeneity. Due to limited studies in this meta-analysis, we cannot undertake the meta-regression. Unfortunately, we did not detect ethnicity and HWE status were account for high heterogeneity. However, sensitivity analysis indicated our data were stable and robust.

Although we found the positive finding, the limitations of this meta-analysis should be taken into careful consideration. First, RA is a multifactorial disease,

\section{Begg's funnel plot with pseudo $95 \%$ confidence limits}

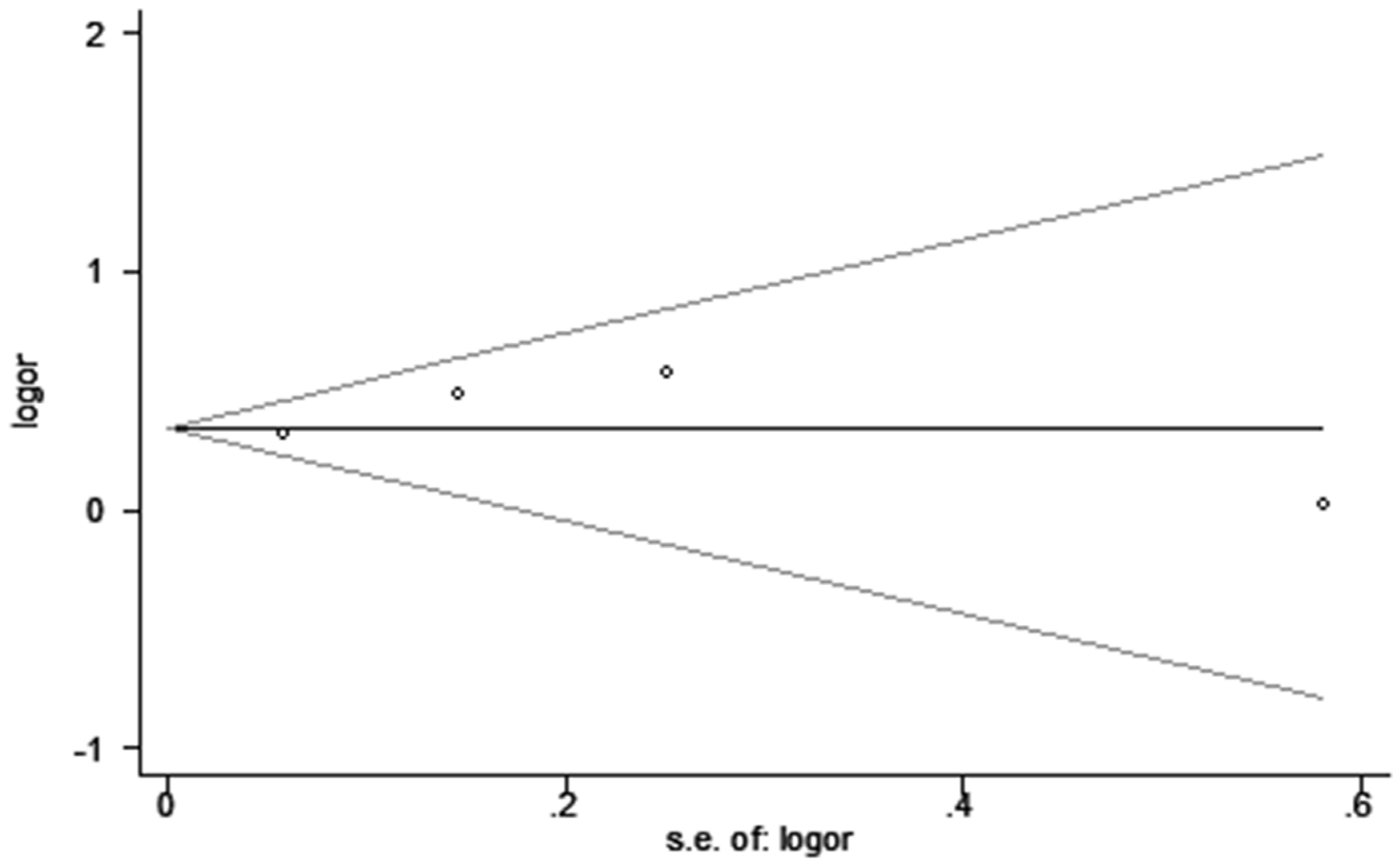

Figure 4: Begg's tests between AIRE gene rs2075786 polymorphism and RA risk (AA vs. GG). 
and thus the function of single SNP is limited. Second, the sample sizes of some individual studies were very small, which could deviate from the truly results. Third, it is worth noting that this meta-analysis only contains one studies about Caucasians, and the result should be interpreted with caution. Fourth, only four studies were included in this metaanalysis. Fifth, the heterogeneity of some genetic models in this meta-analysis is high. Sixth, genotyping methods were different in some studies, which will affect the bias. Finally, no further subgroup analyses such as smoking and age were conducted due to the lack of eligible data.

In summary, AIRE rs275786 polymorphism was associated with the increased risk of RA, which may be viewed as a new biomarker to early screening and prevention of RA

\section{MATERIALS AND METHODS}

\section{Search strategy and selection criteria}

Two investigators carried out a systematic electronic search independently in PubMed, EMBASE and China Knowledge Resource Integrated Database to identify relevant studies. The following key search terms: "autoimmune regulator," "AIRE," "APECED," "polymorphism," "single nucleotide polymorphism," "SNP" "rheumatoid arthritis". No restrictions were placed on the search. Additional initially omitted studies (such as reference lists of identified studies) have been identified by hand screening.

Eligible studies conformed to the following criteria: (1) investigating the relationship between AIRE rs2075786 polymorphism and risk of RA; (2) sufficient data for calculating the pooled odds ratio (ORs) with 95\% confidence interval (CI); (3) case-control studies; (4) studied on human beings. Exclusion criteria were as follows: (1) duplicate studies; (2) lack of enough genotype data or data for calculating genotype distribution; (3) not case-control studies; (4) case only studies.

\section{Data extraction and quality assessment}

Two investigators reviewed and extracted data independently in accordance with the inclusion criteria. From each study, the following information was extracted: name of first author, publication year, country of origin, ethnicity, numbers of cases and controls, and cancer type. When studies included subjects of more than one ethnicity, genotype data were extracted separately. The NewcastleOttawa Scales (NOS) were used to assess the quality of the selected studies [21]. The discrepancies were resolved by discussion or consulting with a third reviewer.

\section{Statistical analysis}

All statistical analyses were performed using the Stata 11.0 software (StataCorp, College Station,
TX, USA). Pooled ORs with corresponding 95\% CIs were calculated to evaluate the strength of relationship between AIRE rs2075786 polymorphism and risk of RA. Stratification analyses were carried out by ethnicity and HWE. $P<0.05$ was considered statistically significant. Taking possible between-study heterogeneity into consideration, we considered the presence of significant heterogeneity at the $10 \%$ level of significance and values of $\mathrm{I}^{2}$ exceeding $50 \%$ as an indicator of significant heterogeneity. When no heterogeneity was found with $P>0.10$ or $\mathrm{I}^{2}<50 \%$, a fixed-effect model was used. Otherwise, a random-effects model was applied [22]. Sensitivity analysis was conducted to determine the effect on the test of heterogeneity and evaluate the stability of the results by omitting each study in turn. Genotype distributions in the controls were tested for confirmation of HWE using the $\chi^{2}$ test. Publication bias was evaluated by visual inspection of symmetry of Begg's funnel plot and assessment of Egger's test [23]; $P<0.05$ was regarded as representative of statistical significance.

\section{CONFLICTS OF INTEREST}

The authors declare no conflicts of interest.

\section{REFERENCES}

1. Alamanos Y, Voulgari PV, Drosos AA. Incidence and prevalence of rheumatoid arthritis, based on the 1987 American College of Rheumatology criteria: a systematic review. Semin Arthritis Rheum. 2006; 36:182-188.

2. Carbonell J, Cobo T, Balsa A, Descalzo MA, Carmona L, and SERAP Study Group. The incidence of rheumatoid arthritis in Spain: results from a nationwide primary care registry. Rheumatology (Oxford). 2008; 47:1088-1092.

3. Pedersen JK, Kjaer NK, Svendsen AJ, Horslev-Petersen K. Incidence of rheumatoid arthritis from 1995 to 2001: impact of ascertainment from multiple sources. Rheumatol Int. 2009; 29:411-415.

4. Scott DL, Wolfe F, Huizinga TW. Rheumatoid arthritis. Lancet. 2010; 376:1094-1108.

5. Ponder BA. Cancer genetics. Nature. 2001; 411:336-341.

6. Nagamine K, Peterson P, Scott HS, Kudoh J, Minoshima S, Heino M, Krohn KJ, Lalioti MD, Mullis PE, Antonarakis SE, Kawasaki K, Asakawa S, Ito F, Shimizu N. Positional cloning of the APECED gene. Nat Genet. 1997; 17:393-398.

7. Finnish-German APECED Consortium. An autoimmune disease, APECED, caused by mutations in a novel gene featuring two PHD-type zinc-finger domains. Nat Genet. 1997; 17:399-403.

8. Bruserud O, Oftedal BE, Wolff AB, Husebye ES. AIREmutations and autoimmune disease. Curr Opin Immunol. 2016; 43:8-15.

9. Aricha R, Feferman T, Berrih-Aknin S, Fuchs S, Souroujon MC. Experimental myasthenia gravis in Aire-deficient 
mice: a link between Aire and regulatory T cells. Ann N Y Acad Sci. 2012; 1275:107-113.

10. Kekalainen E, Pontynen N, Meri S, Arstila TP, Jarva H. Autoimmunity, Not a Developmental Defect, is the Cause for Subfertility of Autoimmune Regulator (Aire) Deficient Mice. Scand J Immunol. 2015; 81:298-304.

11. Haljasorg U, Bichele R, Saare M, Guha M, Maslovskaja J, Kond K, Remm A, Pihlap M, Tomson L, Kisand K, Laan M, Peterson P. A highly conserved NF-kappaB-responsive enhancer is critical for thymic expression of Aire in mice. Eur J Immunol. 2015; 45:3246-3256.

12. Liu Y, Zhang H, Zhang P, Meng F, Chen Y, Wang Y, Yao Y, Qi B. Autoimmune regulator expression in thymomas with or without autoimmune disease. Immunol Lett. 2014; 161:50-56.

13. Terao C, Yamada R, Ohmura K, Takahashi M, Kawaguchi T, Kochi Y, Okada Y, Nakamura Y, Yamamoto K, Melchers I, Lathrop M, Mimori T, Matsuda F, and Human Disease Genomics Working Group, RA Clinical and Genetic Study Consortium. The human AIRE gene at chromosome 21q22 is a genetic determinant for the predisposition to rheumatoid arthritis in Japanese population. Hum Mol Genet. 2011; 20:2680-2685.

14. Colobran R, Gimenez-Barcons M, Marin-Sanchez A, Porta-Pardo E, Pujol-Borrell R. AIRE genetic variants and predisposition to polygenic autoimmune disease: The case of Graves' disease and a systematic literature review. Hum Immunol. 2016; 77:643-651.

15. Turunen JA, Wessman M, Forsblom C, Kilpikari R, Parkkonen M, Pontynen N, Ilmarinen T, Ulmanen I, Peltonen L, Groop PH. Association analysis of the AIRE and insulin genes in Finnish type 1 diabetic patients. Immunogenetics. 2006; 58:331-338.
16. Pforr J, Blaumeiser B, Becker T, Freudenberg-Hua Y, Hanneken S, Eigelshoven S, Cuyt I, De Weert J, Lambert J, Kruse R, Nothen MM, Betz RC. Investigation of the p.Ser278Arg polymorphism of the autoimmune regulator (AIRE) gene in alopecia areata. Tissue Antigens. 2006; 68:58-61.

17. van Eden W, Spiering R, Broere F, van der Zee R. A case of mistaken identity: HSPs are no DAMPs but DAMPERs. Cell Stress Chaperones. 2012; 17:281-292.

18. Shao S, Li XR, Cen H, Yin ZS. Association of AIRE polymorphisms with genetic susceptibility to rheumatoid arthritis in a Chinese population. Inflammation. 2014; 37:495-499.

19. Feng ZJ, Zhang SL, Wen HF, Liang Y. Association of rs2075876 polymorphism of AIRE gene with rheumatoid arthritis risk. Hum Immunol. 2015; 76:281-285.

20. Garcia-Lozano JR, Torres-Agrela B, Montes-Cano MA, Ortiz-Fernandez L, Conde-Jaldon M, Teruel M, Garcia A, Nunez-Roldan A, Martin J, Gonzalez-Escribano MF. Association of the AIRE gene with susceptibility to rheumatoid arthritis in a European population: a case control study. Arthritis Res Ther. 2013; 15:R11.

21. Stang A. Critical evaluation of the Newcastle-Ottawa scale for the assessment of the quality of nonrandomized studies in meta-analyses. Eur J Epidemiol. 2010; 25:603-605.

22. Higgins JP, Thompson SG. Quantifying heterogeneity in a meta-analysis. Stat Med. 2002; 21:1539-1558.

23. Peters JL, Sutton AJ, Jones DR, Abrams KR, Rushton L. Comparison of two methods to detect publication bias in meta-analysis. JAMA. 2006; 295:676-680. 